\title{
Responsive ParaCEST Contrast Agents
}

\author{
Éva Tóth and Célia S. Bonnet* \\ Centre de Biophysique Moléculaire, CNRS UPR 4301, Université d’Orléans, rue Charles Sadron, CS 80054, \\ 45071 Orléans CEDEX 2, France; eva.jakabtoth@cnrs.fr \\ * Correspondence: celia.bonnet@cnrs.fr
}

Received: 2 May 2019; Accepted: 21 May 2019; Published: 25 May 2019

check for updates

\begin{abstract}
This article aimed at reviewing the advances on the development of paramagnetic complexes used as chemical exchange saturation transfer agents in magnetic resonance imaging. This relatively new type of contrast opens new avenues in the development of MRI probes for molecular imaging, and coordination chemistry lies at the center of such advances. Strategies to detect important biomarkers such as $\mathrm{pH}$, cations, anions, metabolites, enzyme, and $\mathrm{O}_{2}$ were described. The current challenges, limitations, and opportunities in this field of research were discussed.
\end{abstract}

Keywords: molecular imaging; MRI; contrast agents; chemical exchange saturation transfer; lanthanides; transition metal ions

\section{Introduction}

Molecular imaging is gaining increasing interest due to the possibilities to image and understand biochemical processes and to provide early-diagnosis of pathologies. Indeed, conversely to traditional imaging, which looks at the morphology of tissues, molecular imaging characterizes tissues from their physico-chemical point of view $\left(\mathrm{pH}, \mathrm{pO}_{2}\right.$, cations, metabolites, enzymes, etc.). These alterations are known to happen prior to the morphological changes that they trigger. Among all imaging modalities, magnetic resonance imaging (MRI) has the advantage of being a non-invasive technique that can image the whole body without the use of ionizing radiation, and with an excellent resolution. Although traditional MRI can be performed without the use of an imaging probe, contrast agents can enhance the quite low sensitivity of the technique and allow to obtain better anatomical images. In molecular imaging, the use of a contrast agent specific to the event to detect is indispensable. MRI is particularly well-adapted to molecular imaging as MRI contrast agents can be made responsive to a given parameter. Several MRI techniques exist with their own advantages/disadvantages, among those $\mathrm{T}_{1}$-weighted and $\mathrm{T}_{2}$-weighted MRI, which are based, respectively, on the longitudinal and transverse relaxation times of the protons. The contrast agents used for the different techniques are chemically very different as $\mathrm{T}_{1}$ agents are mainly small molecular $\mathrm{Gd}^{3+}$ or $\mathrm{Mn}^{2+}$ complexes, while $\mathrm{T}_{2}$ agents are typically superparamagnetic nanoparticles. The area of responsive $\mathrm{T}_{1}$ and $\mathrm{T}_{2}$ contrast agents have been explored widely in the last few years and excellent reviews have been published on this subject [1-3]. A few years ago, a new type of contrast based on the chemical exchange saturation transfer (CEST) appeared in MRI. Those agents must present exchangeable protons ( $-\mathrm{OH}$ of water/alcohols, $-\mathrm{NH}$ of amides/amines, etc.) in slow exchange with bulk water protons. The magnetization of the exchangeable protons is modulated by a pre-saturation pulse, and the water signal intensity is consequently decreased due to the chemical exchange with the saturated exchangeable protons (Figure 1) [4,5]. CEST MRI contrast is generated based on the decrease of the water signal intensity, linked to the exchange and characterized by the chemical shift of the exchangeable protons, and their exchange rate $k_{\text {ex }}$. In order to observe a CEST effect, this exchange rate $\left(k_{\mathrm{ex}}\right)$ must be lower than the chemical shift difference between the exchangeable proton of the CEST agent and the bulk water proton $\left(\Delta \omega=\left|\omega_{\text {CEST }}-\omega_{\text {WAT }}\right|\right)$. Many 
diamagnetic CEST agents have been proposed, and certain metabolites can also act as endogenous contrast agents and be imaged by diaCEST [6]. These diamagnetic probes present small chemical shifts compared to bulk water, and in this chemical shift range, a strong background signal from the tissue magnetization transfer is present. The use of paramagnetic chelates is therefore interesting as the chemical shifts of the probe are larger, enabling to explore a wider range of (faster) exchange rates hence increasing the observable CEST effect. The exploration of faster exchanges also helps reducing the detrimental effects of relaxation. Moreover, the CEST effect will be shifted beyond the tissue magnetization transfer window.

a)

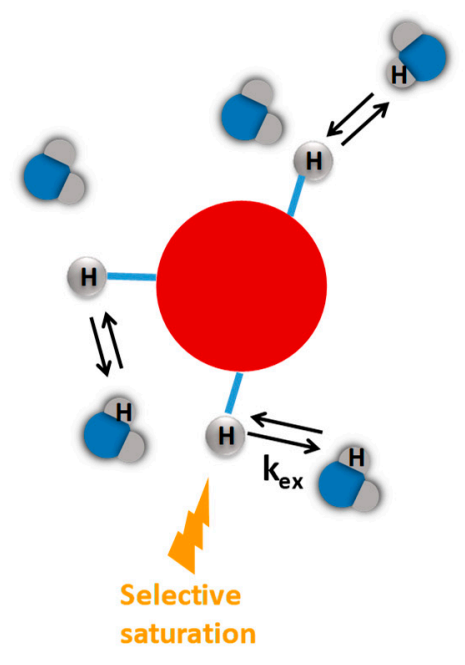

b)

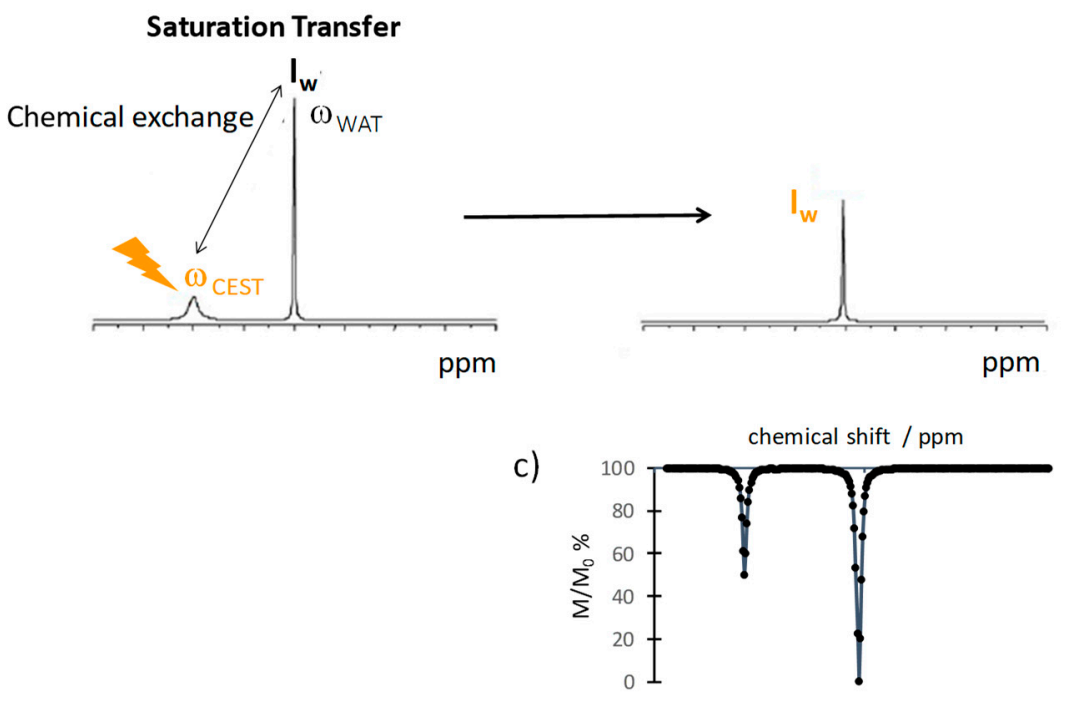

Figure 1. (a) Schematic representation of a chemical exchange saturation transfer (CEST) contrast agent with protons in exchange with those of bulk water; (b) principle of the CEST effect: Upon selective saturation of an exchangeable proton of the CEST agent, the intensity of the NMR peak of bulk water protons is diminished due to chemical exchange between the two proton pools; (c) corresponding CEST- or Z-spectrum.

Complexes of paramagnetic transition metal ions ( $\mathrm{Co}, \mathrm{Ni}, \mathrm{Fe}$, etc.) and $\mathrm{Ln}^{3+}$ (all paramagnetic lanthanide ions, with the exception of $\mathrm{Gd}^{3+}$; most typically $\mathrm{Eu}^{3+}, \mathrm{Tm}^{3+}$, and $\mathrm{Yb}^{3+}$ ) have been explored as ParaCEST agents. Generally, to characterize a ParaCEST contrast agent, CEST-spectra or Z-spectra representing the percentage of decrease of the intensity of the bulk water signal as a function of the irradiation frequency are recorded.

The development of ParaCEST agents as responsive probes are only at their premises compared to $\mathrm{T}_{1}$ - or $\mathrm{T}_{2}$-contrast agents, and very few have been applied in vivo [7]. The future clinical use of ParaCEST agents can be also restricted due to the high power pulses required that can exceed the power deposition limits, quantified as specific absorption rate (SAR) approved by authorities. Indeed, the efficient radiofrequency saturation of the exchanging protons might require strong radiofrequency intensities, which could cause tissue warming.

The aim of this review is to give an overview of the chemical design of responsive ParaCEST agents and the current limitations and challenges in the field. Compared to $\mathrm{T}_{1}$-contrast agents, the rational design of ParaCEST contrast agents remains more challenging due to the difficulties in predicting the proton exchange rate. Recent studies have shown that ab initio calculations can reproduce experimental exchange rates with reasonable precision [8], however these calculations remain long and not easily accessible. Another current limitation of ParaCEST is its sensitivity, which is lower than that of $\mathrm{T}_{1}$-contrast agents. Approaches to maximize the number of exchangeable protons and increase sensitivity are therefore an active area of research [9] and will also be discussed in view of 
creating responsive probes. Finally, quantitative detection of a given biomarker or tissue parameter is highly desirable and several approaches have been explored in this objective. All these current efforts should converge and help the development of ParaCEST agents towards in vivo applications. We will focus on agents responsive to important biological parameters, such as $\mathrm{pH}$, cations, anions, metabolites or DNA, the redox status of tissues, and enzymatic activities.

\section{2. pH-Responsive Probes}

$\mathrm{pH}$ plays an important role in cancers, ischemic lesions, kidney diseases, and infections. It has been shown, for example, that extracellular acidity promotes the invasion of metastatic cells and that alkaline $\mathrm{pH}$ around tumors could contribute to a good therapeutic solution [10]. $\mathrm{pH}$ can then be used to stage tumors, improve prognosis, and guide anticancer therapies. By essence, proton exchange processes are usually acid- or base-catalyzed, thus the exchange rate is dependent on the $\mathrm{pH}$, making ParaCEST contrast agents ideal responsive probes for $\mathrm{pH}$. Typically, amine and amide functions have been used for this purpose mainly in $\mathrm{Ln}^{3+}$-based complexes [11-13], but more recently in $\mathrm{Co}^{2+}[14,15]$ and $\mathrm{Fe}^{2+}$ complexes as well [16]. Similarly, the $\mathrm{pH}$ dependence of hydroxyl groups have been also exploited $[17,18]$. For $\mathrm{Ln}^{3+}$ complexes, water molecules directly coordinated to the $\mathrm{Ln}^{3+}$ ion have also been used [19]. Although CEST effects remain difficult to predict, the vast majority of these probes are based on the influence of $\mathrm{pH}$ directly on the proton exchange rate of the groups leading to the CEST signal. In other cases, the $\mathrm{pH}$ effect is more indirect. For instance, the CEST effect of the $[\mathrm{Fe}(\mathrm{TAPC})]^{2+}$ complex (Scheme 1) originates from the amine groups but is modulated by the protonation of the unbound 2-amino-6-picolyl pendent arms. Recent studies have also highlighted the importance of appended amine functions on the $\mathrm{pH}$-dependent CEST effect generated by a water molecule directly coordinated to $\mathrm{Eu}^{3+}[20]$.

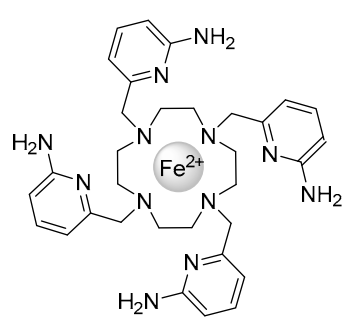

$[\mathrm{Fe}(\mathrm{TAPC})]^{2+}[16]$

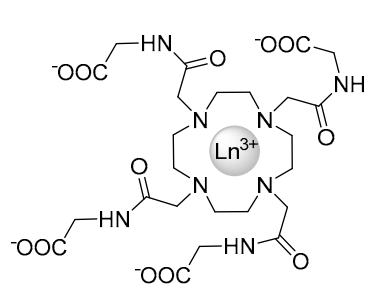

$\operatorname{Ln}($ DOTAM-Gly) [21]

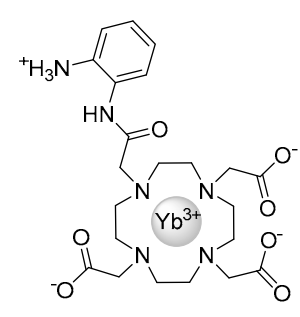

$\mathrm{Yb}($ DO3A-OAA) [13]

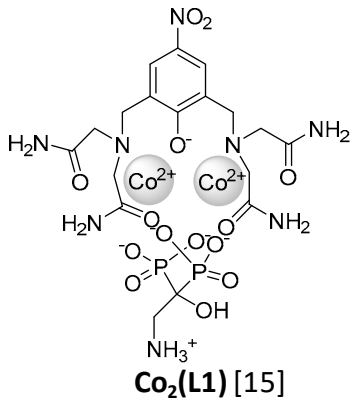

$\mathrm{Co}_{2}(\mathrm{~L} 1)[15]$

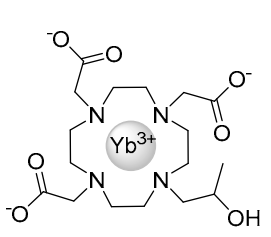

Yb(HP-DO3A) [17]

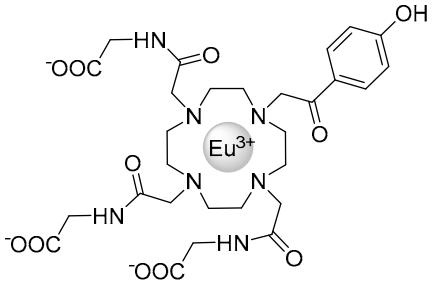

$\mathrm{Eu}(\mathrm{L2})[19]$

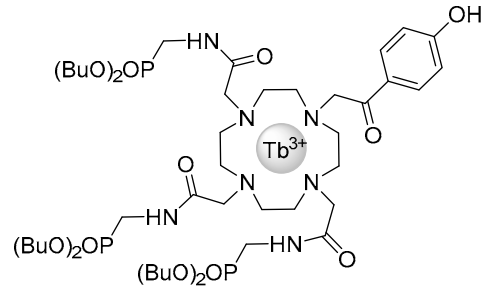

$\mathrm{Tb}(\mathrm{L3})[25]$

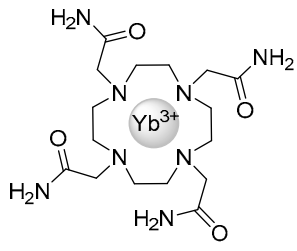

Yb(DOTAM) [27]

Scheme 1. pH-dependent ParaCEST probes.

However, to practically detect $\mathrm{pH}$, ratiometric methods need to be developed. Typically, ratiometric approaches allow for quantifying the biomarkers by circumventing the problem of unknown local concentration of the imaging probe. Indeed, the MRI signal is dependent not only on the concentration of the biomarker, but also on the local concentration of the responsive agent. Different approaches have been exploited to tackle this problem. The first one relies on the presence of at least two pools of exchangeable protons within a single probe. This is the case of the $\mathrm{Ln}^{3+}$ complexes of DOTAM-Gly (Scheme 1) for which the protons of both the coordinated water molecule and the amide function can 
give rise to CEST effects, depending on the $\mathrm{Ln}^{3+}$ used. The exchange rate of the amide protons is base-catalyzed and is strongly affected by $\mathrm{pH}$, whereas the exchange rate of the water protons is $\mathrm{pH}$ independent. The use of a mixture of $\mathrm{Yb}$ (DOTAM-Gly) (CEST effect arising from amide protons and increasing from $\mathrm{pH} 6$ to 8 ) and $\mathrm{Eu}$ (DOTAM-Gly) (CEST effect arising from $\mathrm{H}_{2} \mathrm{O}$ coordinated to $\mathrm{Eu}^{3+}$ and $\mathrm{pH}$ independent) complexes, has been successfully used for ratiometric $\mathrm{pH}$ determination [21]. In order to use a single $\mathrm{Ln}^{3+}$ probe, the complexes of the same ligand with lighter $\mathrm{Ln}^{3+}$ complexes $\left(\mathrm{Pr}^{3+}, \mathrm{Nd}^{3+}\right.$, and $\left.\mathrm{Eu}^{3+}\right)$, and which display two CEST resonances corresponding to the water molecule and the amide protons simultaneously, have been exploited [11]. A similar method has been explored with $\mathrm{Yb}$ (DO3A-oAA) (Scheme 1), which shows simultaneously two CEST effects arising from the protons of the amine and the amide groups. In this case, both CEST effects are dependent on the $\mathrm{pH}$, but their ratio shows an excellent correlation with $\mathrm{pH}$ [13], which allowed the successful use of this probe for $\mathrm{pH}$ determination in vivo [12,22]. Recently, the same type of approach has been used for the dicobalt $\mathrm{Co}_{2}(\mathrm{~L} 1)$ complex (Scheme 1). The ratio of the CEST effects arising from the amine and from the two overlapping amides is linear with the $\mathrm{pH}$, and the $\mathrm{pH}$ sensitivity in the physiological range is one of the highest reported so far [15].

The second approach for independent $\mathrm{pH}$ determination is based on the presence of two isomers of the same complex displaying one exchanging pool of protons each. An excellent example is $\mathrm{Yb}$ (HP-DO3A) (Scheme 1) for which the CEST spectra display two peaks corresponding to the exchangeable protons of the hydroxyl groups of the two isomers. The two signals have been exploited to set up a ratiometric curve, which is independent of the probe concentration [17]. This method has been successfully used in vivo to map extracellular $\mathrm{pH}$ in murine melanoma [23].

Finally, the third method relies on an important shift of the CEST peak upon $\mathrm{pH}$ changes. Eu(L2) (Scheme 1), bears a phenolic group and its CEST effect arises from the water molecule directly coordinated to $\mathrm{Eu}^{3+}$. Upon deprotonation of the phenol, the protons of the bound water molecule undergo a 5 ppm shift [19]. This complex has been used to map pH in mouse kidneys in vivo [24]. The use of a similar $\mathrm{Tb}^{3+}$ complex with three appended dibutylphosphonate side-chains $\mathrm{Tb}(\mathrm{L} 3)$ (Scheme 1) to slow down water exchange rate has enabled to greatly amplify the shift (56 ppm) upon deprotonation of the phenolic group. A direct $\mathrm{pH}$ determination with no interference from the tissue magnetization transfer signal is therefore possible [25].

It should be noted that CEST effects are also highly dependent on temperature and several of these $\mathrm{pH}$-dependent probes are also simultaneously used for temperature determination. In these cases, $\mathrm{pH}$ is assessed via the first or second ratiometric method described above and temperature was simultaneously determined from the chemical shift of the CEST peak using the high temperature sensitivity displayed by lanthanide-induced shift, which is itself unaffected by $\mathrm{pH}[17,26]$.

One of the flaws of ParaCEST MRI is its low sensitivity, which requires using quite important concentrations of contrast agents (typically in the $\mathrm{mM}$ range). To circumvent this problem and increase the sensitivity of the probes, $\mathrm{Yb}(\mathrm{DOTAM})$ complexes (Scheme 1) have been conjugated to poly(propylene-imine) dendrimers. The large increase of the number of exchangeable amide protons allows for a minimum concentration detected reduced by a factor 4 and 16, respectively, for the first and third generation of dendrimers, with respect to the mononuclear complex [27].

\section{Cation Responsive Probes}

The detection of endogenous cations is receiving increasing attention due to their vital role in living systems. Involved in many fundamental biological processes, they are essential elements for the growth and development of all living organisms. Metal accumulation, transport, distribution and export are tightly regulated by cells through for example transporters and metallochaperones [28]. Disruption in metal ion homeostasis has been associated with numerous pathologies such as cancers, neurodegenerative diseases, or stroke $[29,30]$. Therefore, imaging and quantifying these ions in living systems by non-invasive techniques for a better understanding of their role and distribution, and for early clinical diagnosis is desirable. Optical imaging is the mainstream for their detection in vitro 
and in living systems nowadays. However, the lack of macroscopic resolution and the restriction to surface imaging due to low tissue penetration of light limit the use of this technique. MRI is a good alternative, and recent years have seen a growing number of cation-responsive MRI probes in the literature, mainly $\mathrm{T}_{1}$-based contrast agents [31]. The development of ParaCEST contrast agents for cation detection is limited to few cases and none of them have been applied in vivo. Cation-sensitive probes are typically composed of three parts: (1) $\mathrm{A} \mathrm{Ln}^{3+}$ complexing unit, (2) a part to complex the cation to sense, and (3) a linker between the two. Exchangeable protons can be present on each of these moieties but the rational development of such probes is not easy as the efficacy of such agents will depend on the geometry/distance of the exchangeable protons both with respect to the $\mathrm{Ln}^{3+}$ and to the cation to detect so that to induce observable CEST changes upon cation complexation. Additional requirements involve (1) a good selectivity for the cation to detect, and even for a certain oxidation state (e.g., $\left.\mathrm{Cu}^{+/ 2+}\right)$, (2) an affinity for the cation, which is adapted to its physiological concentration, and (3) a reversible binding in order not to disrupt homeostasis. Calcium, zinc, and copper have been ideal targets for ParaCEST agents as their extracellular concentrations lie in the MRI detectable range (although copper is at the lower limit).

ParaCEST contrast agents, based on a DOTAM derivative with appended iminodiacetate groups for $\mathrm{Ca}^{2+}$ binding, have been developed [32]. A CEST effect is observed both for $\mathrm{Yb}(\mathrm{L} 4)$ and $\mathrm{Eu}(\mathrm{L} 4)$ complexes (see Scheme 2) and it originates respectively from the exchangeable protons of the amide functions, and the coordinated water. These complexes respond to $\mathrm{Ca}^{2+}$ and $\mathrm{Mg}^{2+}$ and CEST effects decrease considerably upon binding. This was attributed to the decrease of the exchange rate of the amide protons upon $\mathrm{Ca}^{2+}$ and $\mathrm{Mg}^{2+}$ binding to $\mathrm{Yb}(\mathrm{L} 4)$. The affinities for these metal ions have been assessed and they are low, suggesting the coordination of only one iminodiacetate arm. Interestingly, while $\mathrm{Yb}(\mathrm{L} 4)$ shows a CEST effect at $-11 \mathrm{ppm}, \mathrm{Yb}(\mathrm{L} 5)$ (Scheme 2) does not show any CEST effect. This was not anticipated as the proton exchange on the two amide nitrogen was expected to be in the appropriate timescale to produce CEST effects. Possibly, the proximity of the carboxylates contributes to a faster proton exchange. This highlights the difficulty of predicting CEST effects. More recently, dinuclear $\mathrm{Eu}^{3+}$ complexes comprising an EGTA moiety for $\mathrm{Ca}^{2+}$ binding $\left(\mathrm{Eu}_{2}(\mathrm{~L} 6)\right.$, Scheme 2$)$ have been studied for their CEST response to $\mathrm{Ca}^{2+}, \mathrm{Mg}^{2+}$ and $\mathrm{Zn}^{2+}$ [33]. These complexes are very similar to a $\mathrm{T}_{1}$ $\mathrm{Ca}^{2+}$ responsive contrast agent, except for the replacement of the DOTA-type coordination sphere of $\mathrm{Ln}^{3+}$ by a DOTAM-type coordination sphere [34]. Amide functions are known to reduce the exchange rate of the water molecule directly coordinated to $\mathrm{Ln}^{3+}$ [35]. Indeed, as a general rule, with carboxylate functions coordinating to the $\mathrm{Ln}^{3+}$, the exchange rate of the hydration water (thus the water protons) is too fast to generate a ParaCEST effect, whereas it becomes observable for the amide (DOTAM) derivatives. Therefore $\mathrm{Eu}_{2}(\mathrm{~L} 6)$ gives rise to a CEST effect from the water molecules coordinated to $\mathrm{Eu}^{3+}$. Unfortunately, no significant change of this CEST effect is detected upon $\mathrm{Ca}^{2+}$ binding, whereas a decrease in the hydration number was observed on the corresponding $\mathrm{Gd}^{3+} \mathrm{T}_{1}$-contrast agent. To explain this, the different charge of the triscarboxylate and the trisamide complexes was shown to strongly affect the pKa of the EGTA moiety. As a consequence, the affinity of EGTA for $\mathrm{Ca}^{2+}, \mathrm{Mg}^{2+}$, and $\mathrm{Zn}^{2+}$ decreases by several orders of magnitude, as assessed by potentiometric titrations. 


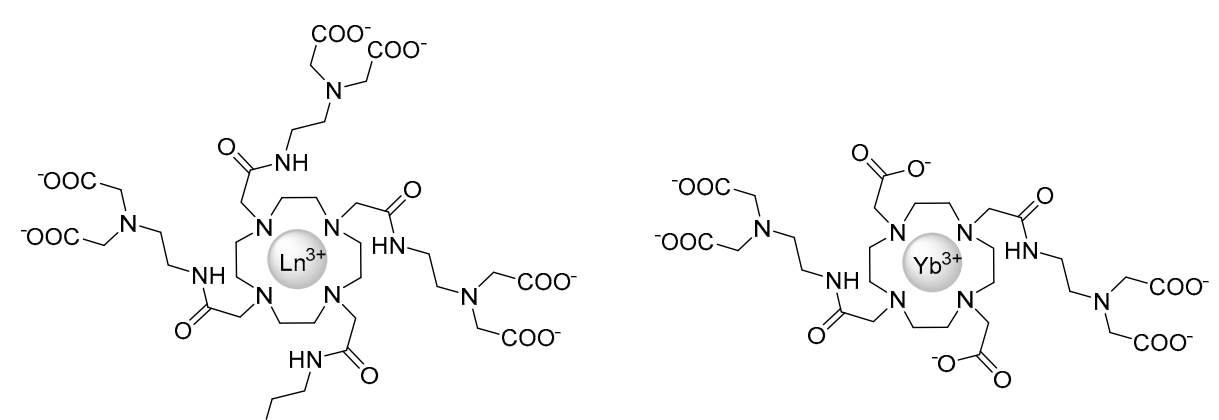

$\mathrm{Yb}(\mathbf{L 5})[32]$

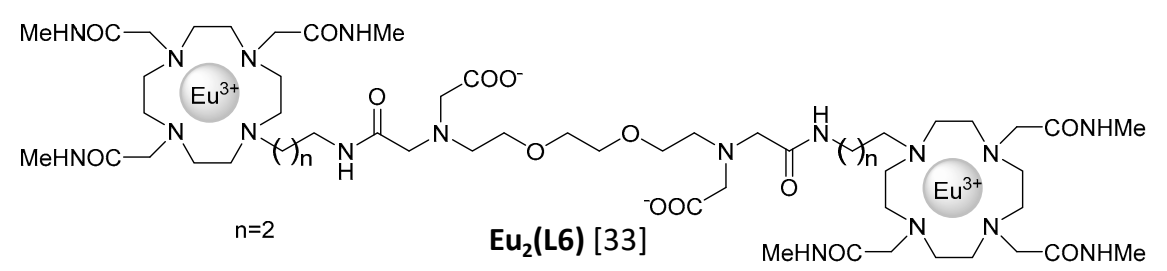
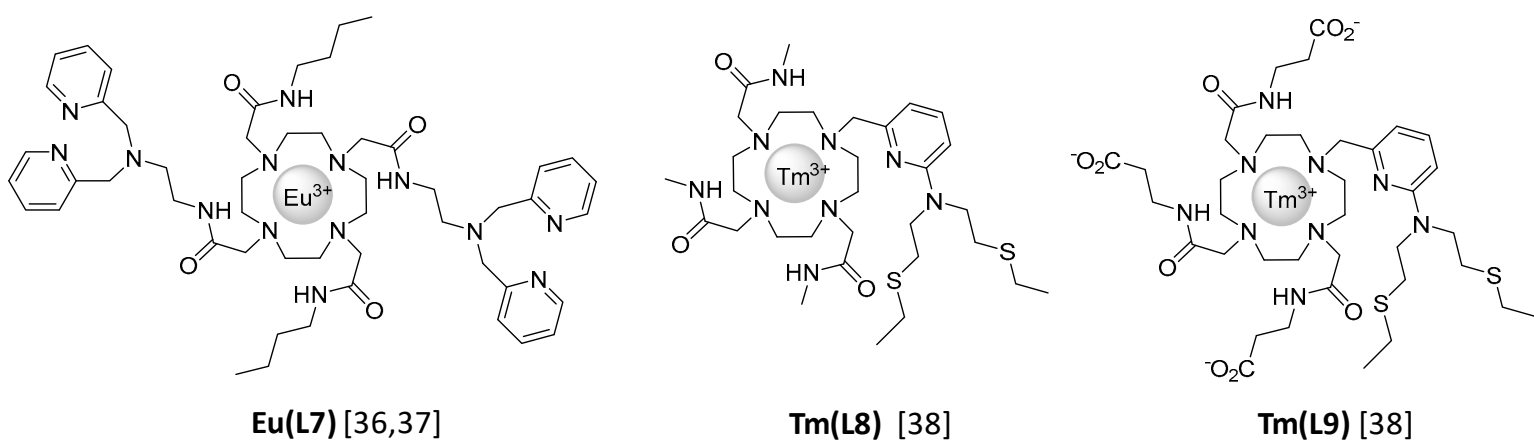

Scheme 2. Cation responsive ParaCEST probes.

The design of a ParaCEST $\mathrm{Zn}^{2+}$ responsive contrast agent based on a similar structure as a $\mathrm{T}_{1}$-responsive probe was more successful. $\mathrm{Eu}(\mathrm{L} 7)$ (Scheme 2) is very similar to a $\mathrm{Zn}^{2+}$-responsive $\mathrm{Gd}^{3+}$ complex except for the replacement of two carboxylate by two amide functions on the macrocycle. Two N,N-bis-(2-pyridyl-methyl)ethylene diamine (BPEN) units have been used for $\mathrm{Zn}^{2+}$ complexation as they are known to efficiently and selectively bind $\mathrm{Zn}^{2+}$ vs. $\mathrm{Ca}^{2+}$ and $\mathrm{Mg}^{2+}$. The $\mathrm{Gd}^{3+}$ complex was successfully used in vivo to detect $\mathrm{Zn}^{2+}$ release after glucose stimulation from the pancreas (in diabetes) [36] and from the prostate (in prostate cancer) [37]. Eu(L7) shows a CEST effect generated by the $\mathrm{Eu}^{3+}$-coordinated water molecule. Upon $\mathrm{Zn}^{2+}$ addition, a broadening of the peaks of the water molecule bound to $\mathrm{Eu}^{3+}$ and of the bulk water is observed and explained by an acceleration of the water (or proton) exchange rate. Potentiometric titrations have evidenced the presence of a $\mathrm{Zn}^{2+}$ hydroxo complex, and it was postulated that this hydroxo complex could accelerate the water exchange rate of the $\mathrm{Eu}^{3+}$-coordinated water. Although the detection is possible at physiological $\mathrm{pH}$, the effect is more important at basic $\mathrm{pH}$. In any case, $\mathrm{Zn}^{2+}$ binding is monitored via a decrease of the CEST effect.

More recently, two $\mathrm{Tm}^{3+}$ complexes were also reported for $\mathrm{Zn}^{2+}, \mathrm{Cu}^{2+}$, and $\mathrm{Cu}^{+}$detection (Tm(L8) and Tm(L9), see Scheme 2) [38]. They include softer donor groups (such as thiol functions) and their design is based on previous results using similar $\mathrm{Gd}^{3+}$ complexes as a $\mathrm{T}_{1}$-contrast for $\mathrm{Cu}^{2+} / \mathrm{Cu}^{+}$ detection [39]. The CEST effects of each $\mathrm{Tm}^{3+}$ complex arise from the exchangeable amide protons and the positively-charged $\mathrm{Tm}(\mathrm{L} 8)$ is more sensitive than the neutral $\mathrm{Tm}(\mathrm{L} 9)$. Upon $\mathrm{Cu}^{+}$coordination, a 1:1 TmL:Cu complex is formed, whereas upon $\mathrm{Cu}^{2+}$ and $\mathrm{Zn}^{2+}$ coordination, 2:1 TmL:M complexes are formed. The addition of $\mathrm{Cu}^{+}, \mathrm{Cu}^{2+}$, or $\mathrm{Zn}^{2+}$ increases the exchange rate of the amide protons resulting in a complete disappearance of the CEST signal. 
In summary, very few ParaCEST agents have been developed for cation detection so far. They are all characterized by a decreasing CEST effect upon cation coordination and by a lack of selectivity for a given cation. This certainly explains why none of these systems have yet been applied in vivo.

\section{Probes Responsive to Negatively-Charged Systems: DNA and Metabolites}

The detection of DNA by MRI remains really challenging due to the low sensitivity of MRI, the low concentration (well below $1 \mu \mathrm{M}$ ), and the intracellular location of DNA, requiring a contrast agent that would penetrate the cell in high quantity. However, gene delivery systems can carry a high payload of DNA that can be detectable by MRI. Therefore MRI systems, not specific for a DNA sequence, have been developed. This is the case of the polymeric ParaCEST MRI system Eu(L10) (Scheme 3) [40]. A decrease in the CEST effect generated by the coordinated water molecule upon DNA binding is obtained and it has been shown that one monomeric $\mathrm{Eu}^{3+}$ complex is bound per phosphate group of DNA. The dinuclear $\mathrm{Nd}_{2}$ (L11) (Scheme 3) system is also a probe for DNA detection [41]. CEST effect is generated by the amide groups of the system. The advantage of this dinuclear complex is a high number of exchangeable protons largely increasing the sensitivity. The complex is highly sensitive to carbonate, which upon binding leads to a decrease of the CEST effect, and diethylphosphate has the same effect. On the contrary, the CEST effect is enhanced upon DNA binding, but this enhancement is dependent upon the secondary structure of DNA; hairpin DNA being the most efficient. It was shown on the $\mathrm{Eu}^{3+}$ analogue that DNA binding leads to a displacement of the water molecule on each $\mathrm{Eu}^{3+}$ center. DNA also displaces carbonate when bound to the complex.

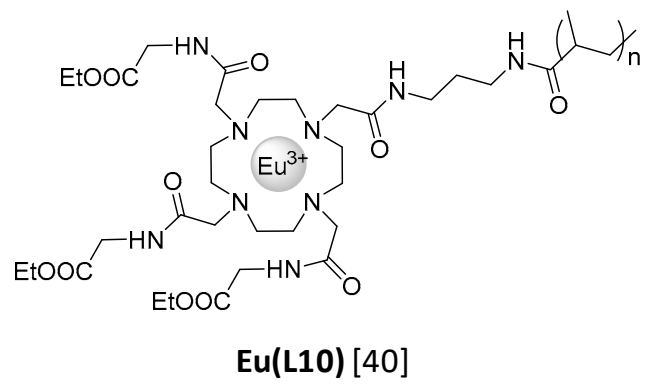<smiles>NC(=O)CN1CCN(CC(N)=O)CCN(Cc2ccc(CN3CCN(CC(N)=O)CCN(CC(N)=O)CC3)cc2)CCN(CC(N)=O)CC1</smiles><smiles>CC(O)CN1CCN(CC(C)O)C[N+](CC(C)O)(CC(C)O)CN(CC(C)O)C1</smiles>

$\mathrm{Eu}(\mathrm{S}-\mathrm{THP})[44,45]$

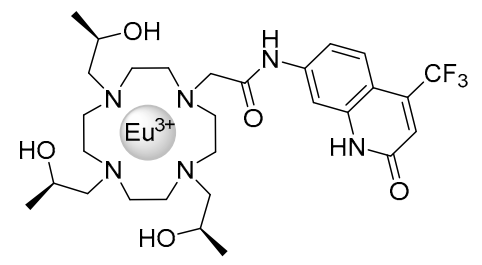

$\mathrm{Eu}(\mathrm{THPC})[46]$<smiles>O=C(O)CN1CCN2CCN(CC(=O)O)C[NH+](CC(=O)O)CN(CC1)C2</smiles>

$\mathrm{Eu}(\mathrm{DO} A)$ [49]<smiles>CCCC[14CH2]C(C)(C)CCCC</smiles>

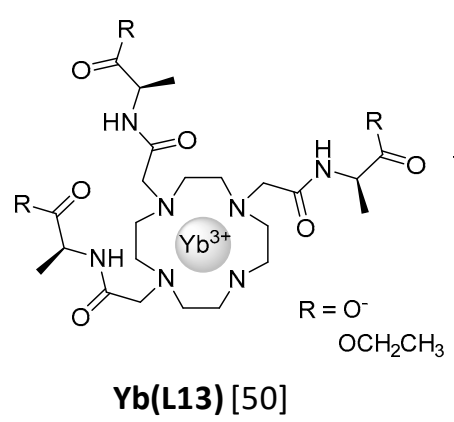

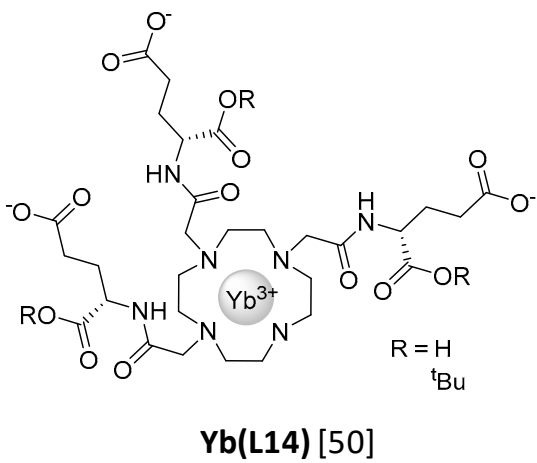

Scheme 3. DNA and metabolite responsive ParaCEST probes. 
Imaging and tracking metabolites holds great promise for the future of medicine. Indeed, metabolites represent the intermediates and products associated with metabolic pathways. Physiological and pathological processes, such as diseases, activate or deactivate these pathways and result in changes of metabolite concentrations. Just to cite a few, phosphate groups play a biochemical role in the regulation of cellular processes, and their misregulation can result in cancer, diabetes, and obesity. Lactate is overproduced by tumors and its export to the extracellular space is supposed to be a key step in the formation of metastases [42]. Therefore tracking these metabolites by MRI would allow to better understand metabolism and to detect diseases at an early stage. Very often the MRI contrast agents are positively charged and the interaction with negatively charged metabolites occurs through the replacement of a water molecule directly coordinated to the $\mathrm{Ln}^{3+}$. Therefore, very few $\mathrm{T}_{1}$-based contrast agents have been developed for such purposes as the replacement of the water molecule by an anion would kill the efficacy of the system. One way to circumvent this is to form non-covalent adduct with the anion, which would modify the accessibility of the inner or outer-sphere water molecules [43]. ParaCEST agents are better suited for such applications as even if the anion-binding occurs at the $\mathrm{Ln}^{3+}$ center, the presence of the hydrophilic anion with $\mathrm{H}$-bonding possibilities might affect the rate of exchange of protons giving rise to CEST effects. Indeed, several ParaCEST complexes have been developed to sense anions such as phosphates, carbonates, lactate, citrate, etc. The main strategies for their detection is represented Figure 2. One of the major difficulties that remains is the selective detection of a given anion.

a)

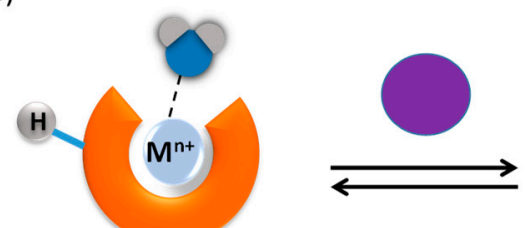

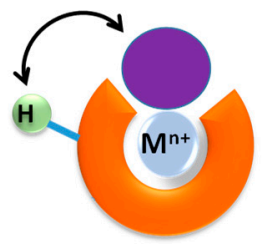

Inner-sphere interaction

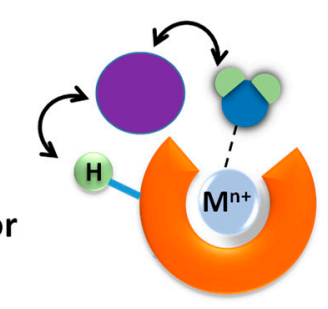

Outer-sphere interaction

b)
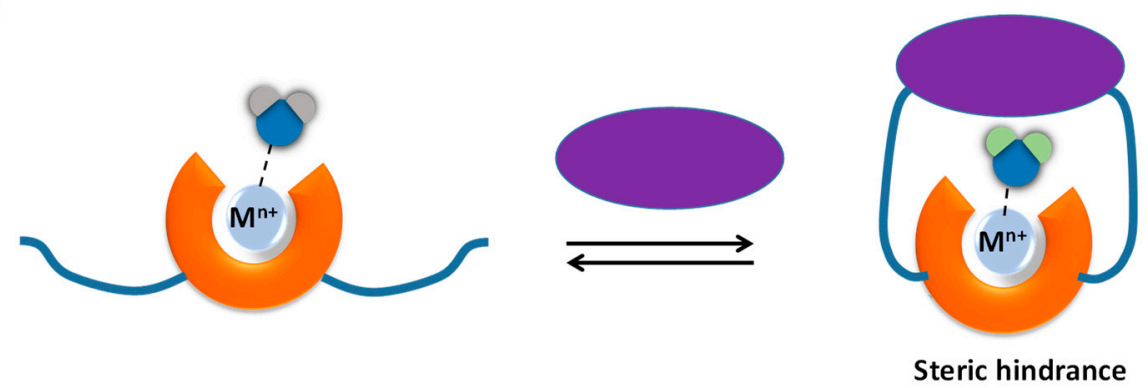

Figure 2. Schematic representation of the different binding modes of anions or metabolites with the ParaCEST agent: (a) Inner or inter-sphere interaction affecting the exchange rate of protons on the ligand and/or on the coordinated water molecule; (b) use of specific group of recognition of a given metabolite, and modification of the exchange rate of the protons from a coordinated water molecule due to steric hindrance.

The Eu(S-THP) complex (Scheme 3) displays a CEST effect, which is $\mathrm{pH}$-dependent, due to the hydroxyl groups in water [44]. This CEST effect is modulated by the presence of phosphate esters. Interestingly, the interaction with methylphosphate resulted in a decrease of the CEST peak concomitant with the appearance of a new CEST peak shifted by $8 \mathrm{ppm}$. It was shown by luminescence measurements that an inner-sphere interaction was occurring with this phosphate monoester (Figure 2a, displacement of the water molecule directly coordinated to $\mathrm{Eu}^{3+}$ ). The apparition of the new CEST peak is due to a change in the acidity of the hydroxyl groups. On the contrary, interaction with 
diethylphosphate resulted in an increase of the existing CEST peak. In this case the water molecule is not displaced and the outer sphere interaction leads to a change in the exchange rate of the hydroxyl protons (Figure 2a). This second sphere binding is selective for phosphate diesters with two terminal oxygens and two identical esters [45]. These studies have shown that it could be possible to detect phosphate containing metabolites present in low $\mathrm{mM}$ concentration. Further studies have been pursued using the same complex and investigating the effect of carbonate, lactate, acetate, citrate, and phosphate [46]. A difference of more than three orders of magnitude in the binding affinity of these biologically relevant anions was found between the most tightly-bound (citrate) and the most weakly-bound (carbonate). With the exception of citrate, the binding is relatively weak, which is adapted to the $\mathrm{mM}$ concentrations of such anions in extracellular fluids. Changes in the ParaCEST spectrum are observed upon binding: For citrate, acetate, and lactate a new CEST peak appears, while the CEST effect is decreased for phosphate and no significant effect is observed for carbonate. With the exception of citrate, the interaction occurs mainly through outer-sphere hydrogen bonding, modulating the exchange rate of hydroxyl protons. Changes in the luminescence spectrum are also observed upon anion binding and the design of Eu(THPC) (Scheme 3), with a carbostyril dye to sensitize $\mathrm{Ln}^{3+}$ luminescence represents a first step towards the development of bimodal anion responsive probes. However, the lower solubility of the complex due the bulky hydrophobic organic dye prevented ParaCEST measurements.

The properties of boronic acids to bind selectively and reversibly molecules containing cis-diols have been used for glucose detection. The Eu(L12) complex (Scheme 3) has been designed with two phenylboronic moieties for such purposes $[47,48]$. The complex gives rise to a CEST effect from the water molecule coordinated to $\mathrm{Eu}^{3+}$ and upon glucose binding, this exchange rate is altered, which can be detected on a CEST spectrum and is based on the mechanism depicted Figure $2 \mathrm{~b}$.

Another approach was used to image lactate looking at the CEST peak of the hydroxyl group of lactate. However, the chemical shift of this peak is very close to that of water making it difficult to distinguish between the two. By using a paramagnetic $\mathrm{Ln}^{3+}$ complex, $\mathrm{Eu}(\mathrm{DO} 3 \mathrm{~A})$ (Scheme 3) which interacts with lactate, the resonance frequency of lactate was shifted by nearly $50 \mathrm{ppm}$ [49]. In vivo images could be obtained after intravenous injection of $\mathrm{Eu}(\mathrm{DO} \mathrm{A})$ ):lactate. As a further step, the development of chiral $\mathrm{Yb}^{3+}$ complexes (Yb(L13) and $\mathrm{Yb}$ (L14), Scheme 3) allowed the discrimination between $\mathrm{D}$ - and L-lactate [50]. Indeed, the CEST spectra of the complexes interacting with lactate showed different frequency resonances depending on the chirality of the lactate.

Despite the number of ParaCEST complexes developed for metabolite sensing, very few in vivo experiments have been performed. $\mathrm{Eu}(\mathrm{L} 12)$ was used to image glucose distribution ex vivo on perfused liver [51]. EuDO3A was used in vivo for lactate detection. Although, it is an important step forward, the complex was co-injected with lactate due to the low sensitivity of the system. This is one major drawback for practical application, the other one being the selectivity for a given metabolite, which remains difficult to obtain due to the non-specific interactions.

\section{Redox-Responsive Probes}

Changes in the redox status of tissues have been linked to different pathologies such as cancer and cardiac diseases. The intra and extracellular redox environment is regulated by redox buffers such as the cysteine/cystine (extracellular), the gluthatione/gluthatione disulfide (intracellular) or the thioredoxin/thioredoxine disulfide (both extra and intracellular) couples. Molecular oxygen is also an important target as hypoxia (low oxygen pressure) characterizes the core of tumors, where there is a poor vascularity. Reactive oxygen species (ROS) or reactive nitrogen species (RNS) such as $\mathrm{H}_{2} \mathrm{O}_{2}, \mathrm{NO}$ are also important targets. They can be present in the intra- or in the extracellular space, but even when they are formed intracellularly, they diffuse or are actively exported to the extracellular space, more easily accessible for MRI detection. Finally, some reductants such as NADH or NADPH are thought to accumulate in poor oxygen areas [52]. Therefore the design of MRI probes whose properties will be modified by those redox active species is an important area of research. Several ParaCEST probes 
have been developed for such purposes and can be classified in two types: Probes for which the redox environment involves a change in the oxidation state of (1) the metal center, or (2) the ligand.

For inducing changes in the metal center, one needs a paramagnetic metal ion that will undergo changes in its redox state within the physiological redox window. The first example is a cobalt complex, $\mathrm{Co}(\mathrm{L} 15)$ (Scheme 4) that can switch from a diamagnetic $\mathrm{Co}^{3+}(\mathrm{OFF})$ to a paramagnetic $\mathrm{Co}^{2+}(\mathrm{ON})$ state [53]. The $\mathrm{NH}$ of the pyrazole groups give rise to a CEST effect for the $\mathrm{Co}^{2+}$ complex at 135 $\mathrm{ppm}$, which is ideal to avoid background of tissue magnetization transfer. The $\mathrm{Co}^{3+}$ complex gives no CEST effect and the switch between $\mathrm{Co}^{2+} / \mathrm{Co}^{3+}$ occurs reversibly with oxygen or reductants such as dithionine and cysteine. The redox potential of the system was measured as $-107 \mathrm{mV}$ vs. NHE (normal hydrogen electrode), which is in the biologically relevant range.

$\mathrm{Ln}^{3+}$ ions exist mainly at the +3 redox state, with the exception of Europium, which has an accessible +2 oxidation state. A redox active $\mathrm{Eu}^{2+} / \mathrm{Eu}^{3+}$ complex (Eu(L16), Scheme 4) has been encapsulated into liposome to improve CEST sensitivity, and the CEST and $\mathrm{T}_{1}$ properties of this system have been studied [54]. In this case, the CEST signal is not modified by oxidation or reduction of the system but the $T_{1}$ signal is. Therefore, this dual imaging mode can be used to perform ratiometric measurements.

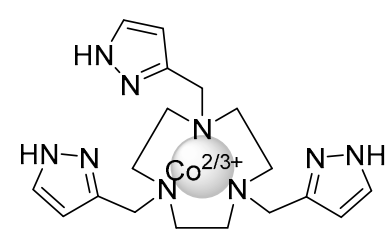

Co(L15) [53]

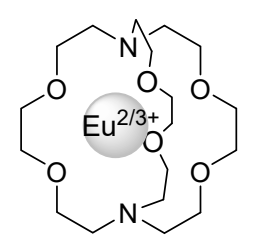

$\mathrm{Eu}(\mathrm{L} 16)[54]$

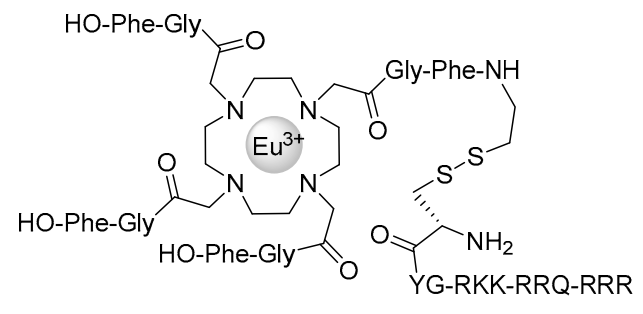

$\mathrm{Eu}(\mathbf{L 2 1})[61]$

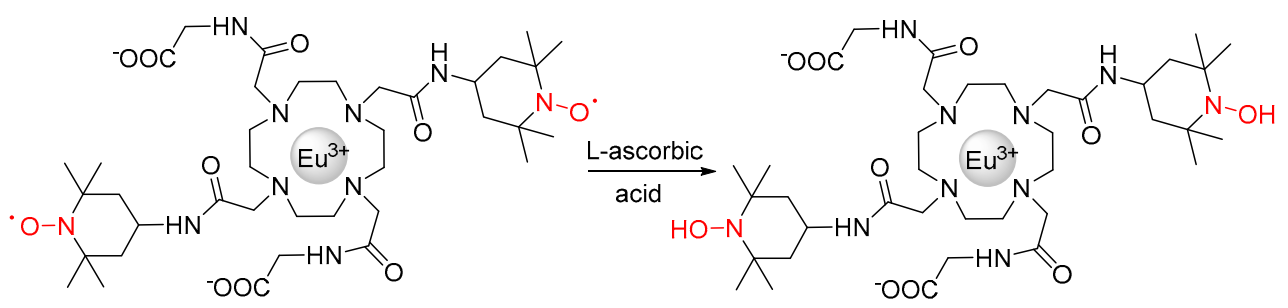

$\mathrm{Eu}(\mathrm{L17})[56]$

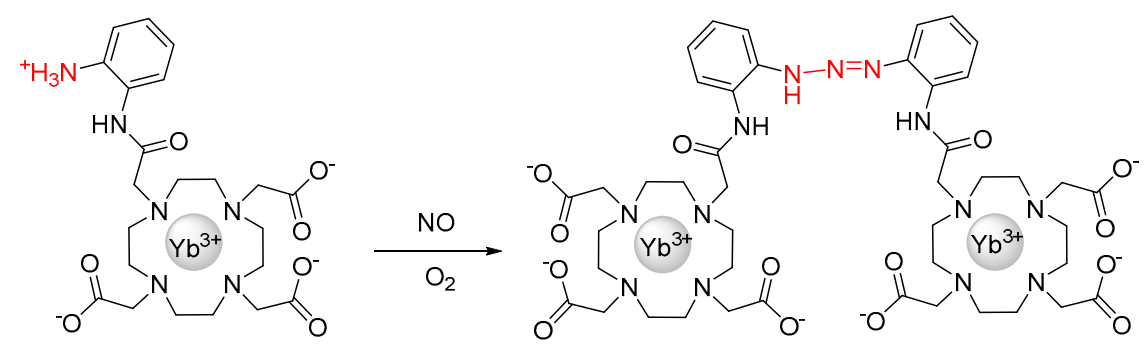

$\mathrm{Yb}$ (D03A-OAA) [57]

Scheme 4. Cont. 

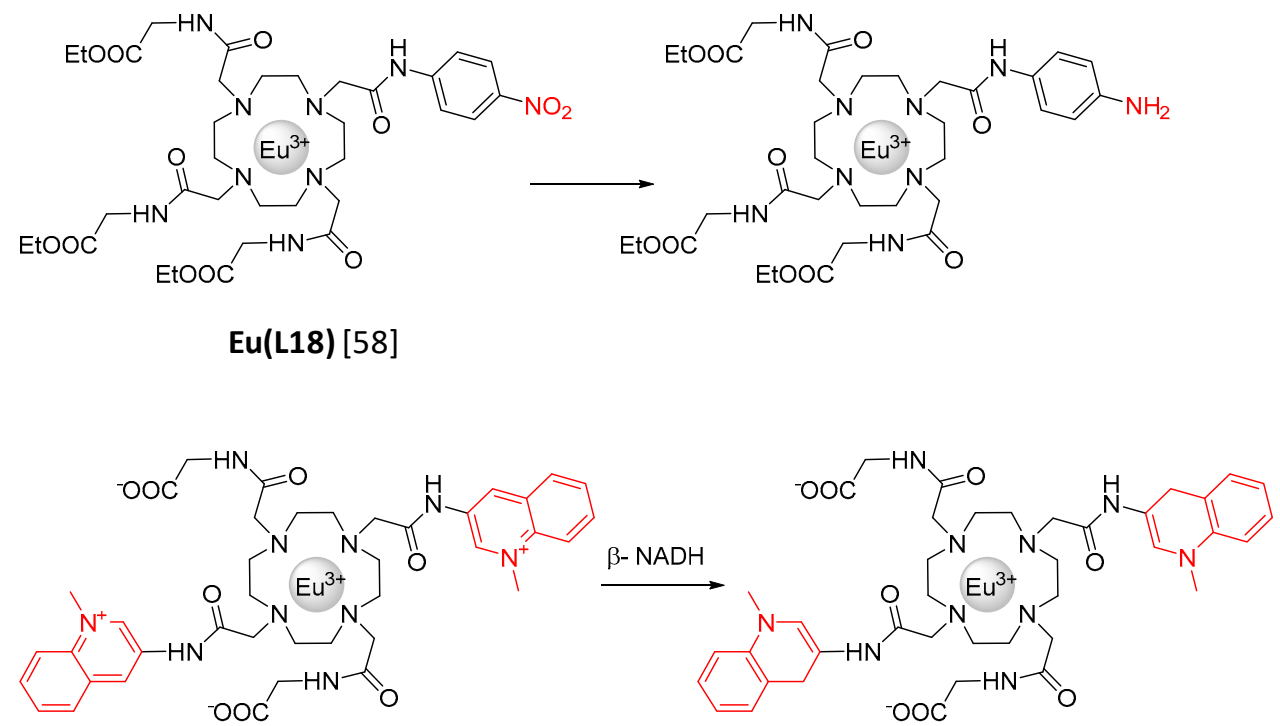

$\mathrm{Eu}(\mathrm{L19)}[59]$

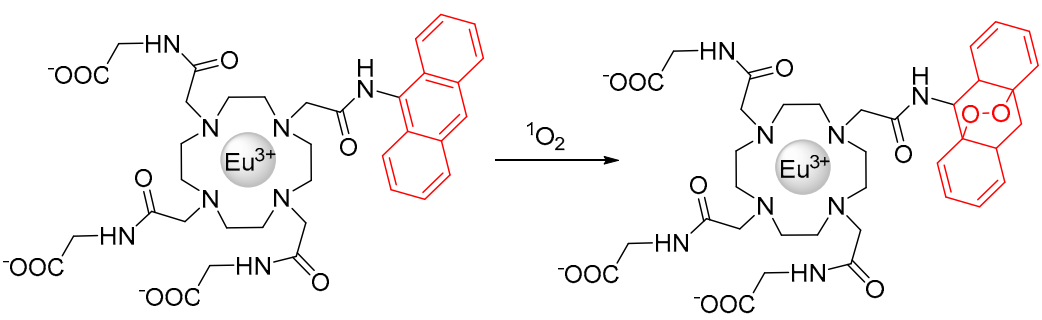

$\mathrm{Eu}(\mathbf{L 2 0})[60]$

Scheme 4. Redox responsive ParaCEST probes.

Other dual mode approaches ( $\mathrm{T}_{1}$ and CEST) have been developed, based on a change of the redox state of the ligand. Contrary to the previous example, in those approaches, the CEST effect is modulated by $\mathrm{T}_{1}$ relaxation (see Figure 3 ). The first example involves a liposome with an encapsulated shift reagent, and a $\mathrm{Gd}^{3+}$ complex grafted at its surface through a disulfide bridge: The $\mathrm{T}_{1}$ and CEST contrast are switched off and on, respectively, after ligand reduction [55]. The shift reagent $\left(\mathrm{Tm}^{3+}\right.$ complex) produces a chemical shift difference between intra and extra-liposomal water and a characteristic CEST effect is obtained from this liposome. When the $\mathrm{Gd}^{3+}$ complexes are grafted at the surface of the liposome, the paramagnetic effect of $\mathrm{Gd}^{3+}$ quenches the CEST effect and the $\mathrm{T}_{1}$ signal is on whereas the CEST signal is off. After cleavage of the disulfide bridge by the TCEP reductant, $\mathrm{Gd}^{3+}$ complexes are quickly washed out, and the $\mathrm{T}_{1}$ signal is off, whereas the CEST signal is switched on. The approach is highly versatile as different stimuli involving a cleavage can be used (enzyme, light, etc.) and only the mode of grafting the $\mathrm{Gd}^{3+}$ complex to the liposome has to be adapted, but on the other hand, for redox sensitive probes, it is mainly limited to the reduction of the disulfide bridge (involving a cleavage). It is also not reversible. The second approach is more specific to redox-based probes as it is using a radical as the paramagnetic quenching species grafted on a molecular complex, which is potentially active in ParaCEST. Eu(L17) (Scheme 4) is a DOTAM complex with two nitroxide free radical units, which acts as $T_{1}$ shortening agents on the surrounding water molecules [56]. The CEST effect of this system is very small. After reduction of the radicals to the diamagnetic bishydroxylamine derivative by $\mathrm{L}$-ascorbic acid, the CEST signal due to the water molecule directly coordinated to $\mathrm{Eu}^{3+}$ is regenerated. A proof-of-concept in vivo experiment has been performed and showed that the complex can be activated with $\mathrm{L}$-ascorbic acid in the bladder. 


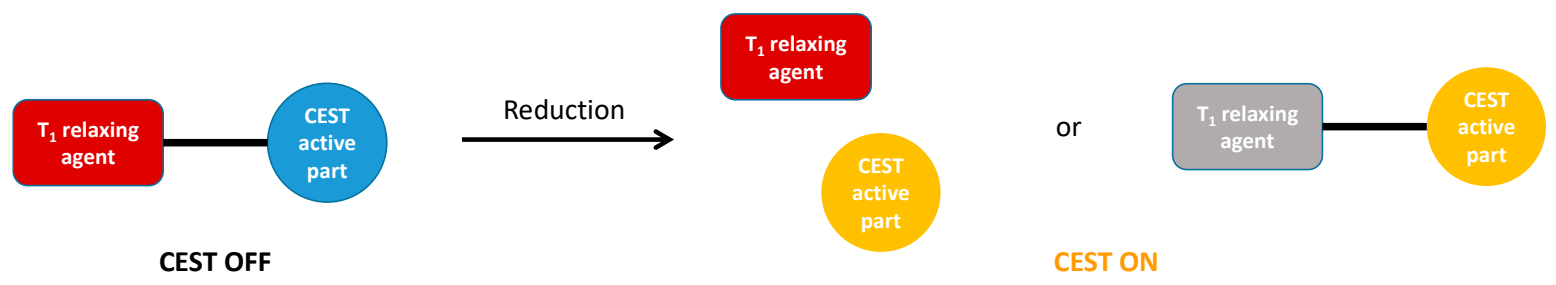

Figure 3. Schematic representation of the modulation of the CEST effect through $\mathrm{T}_{1}$ relaxation: the relaxing agent is a paramagnetic species (either a $\mathrm{Gd}^{3+}$ complex or a radical). When the relaxing agent is close to the CEST active part, the CEST effect is quenched. Upon reduction, either the relaxing agent is cleaved from the CEST active part (for the $\mathrm{Gd}^{3+}$ complex) and becomes far away, either the relaxing agent becomes diamagnetic (reduced radical). In both cases, the CEST effect is switched on.

$\mathrm{Yb}(\mathrm{DO} 3 \mathrm{~A}-\mathrm{oAA})$ (Scheme 1), previously described as a $\mathrm{pH}$ responsive contrast agent, has also been used for the irreversible detection of $\mathrm{NO}$ in the presence of $\mathrm{O}_{2}$ [57]. The complex displays two CEST resonances due to the presence of exchangeable amine and amide protons. Upon reaction with $\mathrm{NO}$, the aromatic amine groups are converted into triazen (see Scheme 4), therefore implying the disappearance of these exchangeable protons and the loss of proximity of the amide protons with $\mathrm{Yb}^{3+}$. As a consequence, the CEST effect is lost after reaction with NO.

Another method for ParaCEST redox responsive agents relies on the change of the electron donating/withdrawing properties of the ligand, which will in turn influence the exchange rate of surrounding protons, therefore modifying the CEST effect. A series of DOTAM-based $\mathrm{Eu}^{3+}$ complexes have been studied, and a relationship between the electronic properties of the ligand and the exchange rate of the water molecule directly coordinated to $\mathrm{Eu}^{3+}$ has been evidenced. A clearly different CEST contrast between an oxidized and reduced form of Eu(L18) (Scheme 4) was obtained [58]. In $\mathrm{Eu}(\mathrm{L} 19)$ (Scheme 4), two $\mathrm{N}$-methylquinolinium units, which are mimics of $\mathrm{NAD}^{+} / \mathrm{NADH}$, have been incorporated as redox active groups [59]. The CEST effect generated by the water molecule is turned on upon reduction of $\mathrm{Eu}(\mathrm{L} 19)$ with $\beta$-NADH. Interestingly, the complex with only one $\mathrm{N}$-methylquinolinium is much less sensitive to the redox environment. These ligand electronic properties were also exploited for the irreversible detection of ${ }^{1} \mathrm{O}_{2}$ using $\mathrm{Eu}(\mathrm{L} 20)$ (Scheme 4) [60]. The 9-anthryl group is used as a specific reactant for ${ }^{1} \mathrm{O}_{2}$ and the water exchange rate (giving rise to the CEST effect) was found to be accelerated after oxidation, which is consistent with the more electron withdrawing properties of the anthryl endoperoxyde. Moreover, the $3 \mathrm{ppm}$ shift observed between the water resonance of the oxidized and reduced form of the complex allowed for a ratiometric detection of ${ }^{1} \mathrm{O}_{2}$.

Finally, a Eu-DOTAM-Gly-Phe-OH complex with a cell penetrating peptide appended through a disulfide bond (Eu(L21) (Scheme 4)) was also studied [61]. The complex is expected to be reduced by intracellular glutathione, and the $\mathrm{Eu}^{3+}$ complex cleaved in this way would be trapped within the cell for a long period of time. The in vivo detection of such systems has yet to be proven.

\section{Enzymatically-Activated PARACEST Probes}

The detection of enzymes has been a major objective in molecular MRI from the very beginning and the first molecular MRI agent reported was also an enzyme-responsive probe [62]. There are multiple reasons for this: (i) Enzymes are primordial in every step of life and represent an important class of biomarkers for any biological or pathological process; (ii) Enzymatic conversion can induce a change in the MRI efficiency of a contrast agent, which makes possible to monitor the activity of the enzyme instead of its simple presence; (iii) due to the catalytical activity, even low quantities of enzymes can convert a large amount of the MRI probe, thereby strongly reducing the detection limit, which helps overcome the challenges of the low sensitivity of MRI; (iv) typically, enzymatic reactions possess high specificity; (v) certain design strategies provide a platform technology with relative ease 
in adapting the MRI probe to the detection of different enzymatic activities. Additionally, detection might be extended to multiple imaging modalities by small changes in the chemical design.

In contrast to the high chemical diversity of enzyme-activated $\mathrm{T}_{1}$ - or $\mathrm{T}_{2}$-agents reported in the literature, advances in the development of enzyme-responsive ParaCEST probes have been more modest. In general, enzymatic conversion of the agent can yield a detectable ParaCEST change by generating or removing exchangeable protons in the structure and by modifying the chemical shift or the exchange rate of such protons.

The first example of an enzymatic ParaCEST agent by Pagel and coll. was a Tm(DOTA) chelate appended with a DEVD peptide sequence at its C-terminus via a peptide bond (Tm(DOTA-DEVD), Scheme 5) [63]. The amide proton gives rise to a CEST effect at $-51 \mathrm{ppm}$. Upon cleavage of the peptide with caspase-3, a protease implicated for instance in apoptosis, the amide is converted into an amine function. This leads to the disappearance of the CEST at $-51 \mathrm{ppm}$ and the appearance of a much smaller effect at $+4 \mathrm{ppm}$, attributed to the amine protons. The Tm(DOTA-DEVD) probe had good selectivity for caspase-3 relative to the similar protease caspase-8. While the CEST effect of the amine appears upon enzymatic cleavage, which is usually an advantage, the signal related to the amide was found to be more robust and practically more useful for detection, despite its disappearance. To validate the monitoring of this disappearance, the authors proposed a ratiometric approach, referred to as CatalyCEST [64]. It combines the enzymatic probe with an enzymatically unresponsive ParaCEST agent ( $\mathrm{Yb}$ (DOTAM-Gly), see Scheme 1) as a reference that has a unique ParaCEST frequency in order to track pharmacokinetics and biodistribution and to account for other conditions that influence CEST but are independent of the enzymatic response. Importantly, this early study also proved that the cleavage by caspase- 3 was rapid enough to allow MRI studies: $3.44 \mathrm{nM}$ of the protease could be detected by using $20 \mathrm{mM}$ concentration of the agent within a reasonable time-frame of $15 \mathrm{~min}$.

If the pharmacokinetics of the responsive agent and the control are different, this can compromise the ratiometric analysis. To circumvent this, the unresponsive probe can be covalently coupled to the responsive unit. This has been realized in a "self-calibrating" ParaCEST MRI contrast agent, $\mathrm{Yb}$ (DO3A-oAA-TML-ester), designed for esterase activity detection (Scheme 5) [65]. The amide proton of the complex gives rise to a CEST effect, which is not sensitive to enzymatic reaction but will report on other changes that might affect CEST. The ester function in the Yb(DO3A-oAA-TML-ester) can be cleaved by an esterase enzyme. The tri-methyl lock moiety formed in this way has unfavorable steric interactions between three methyl groups that induce lactonization to form a hydrocoumarin. As a byproduct of this lactonization, an amide is converted to an amine which generates the CEST effect that can thus report on enzymatic activity. The agent $\mathrm{Yb}$ (DO3A-oAA-TML-ester) could indeed detect esterase enzyme activity in solution and in cell culture medium. The ratio of the enzyme-responsive and the control CEST effects was independent of concentration and $\mathrm{T}_{1}$ relaxation, however, it was dependent on $\mathrm{pH}$, thus this agent was not self-calibrating with respect to $\mathrm{pH}$.

In an analogous self-calibrating design, the probe $\mathrm{Yb}(\mathrm{DO} 3 \mathrm{~A}-\mathrm{oAA}-\mathrm{TML}-\mathrm{Q})$ (Scheme 5) was created to detect the enzyme activity of DT-diaphorase, a flavoenzyme that catalyzes the two electron reduction of quinone, quinone imines, and azo dyes in the presence of $\mathrm{NAD}(\mathrm{P}) \mathrm{H}$ and which is overexpressed in several cancers (non-small cell lung carcinoma, colorectal carcinoma, liver cancers, and breast carcinomas) [66]. Before enzymatic reaction, the probe has one CEST signal at -9 ppm originating from the amide directly linked to the macrocycle. In the presence of DT-diaphorase, the quinone functional group is reduced to a hydroquinone group. This is followed by an intramolecular reaction of the newly formed hydroxyl functional group and the amide bond that releases an amine, giving rise to a new, second CEST signal at $+9 \mathrm{ppm}$. No activation of $\mathrm{Yb}(\mathrm{DO} 3 \mathrm{~A}-\mathrm{oAA}-\mathrm{TML}-\mathrm{Q})$ was observed in a reducing environment in the absence of the enzyme. 


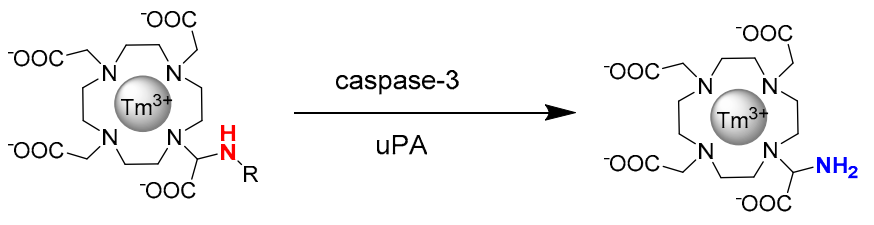

$\mathrm{R}=$ Asp-Val-Glu-Asp- $\mathrm{NH}_{2}: \operatorname{Tm}$ (DOTA-DVED) [63]

R = Arg-Gly-Gly-NH-Cbz : Tm(DOTA-ZGGR) [67]<smiles>CC(=O)Oc1cc(C)cc(C)c1C(C)(C)CC(=O)Nc1ccccc1NC(=O)CN1CCN(CC(=O)O)CCN(CC(=O)O)CCN(CC(=O)O)CC1</smiles>

Yb(D03A-oAA-TML-ester) [65]

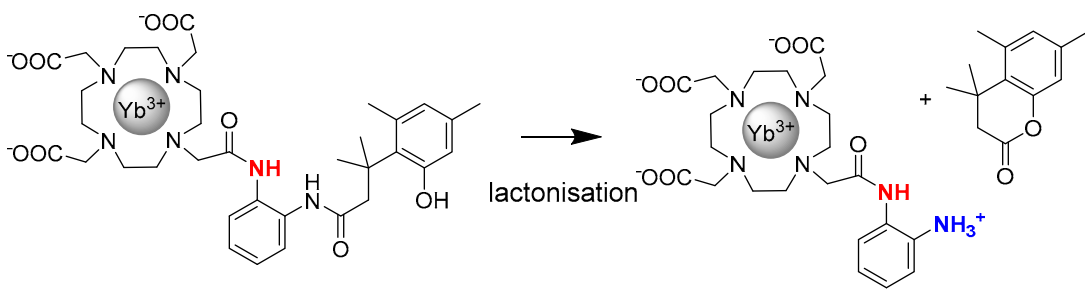<smiles>CC1=C(C)C(=O)C(C(C)(C)CC(=O)Nc2ccccc2NC(=O)CN2CCN(CCO)CCN(CC(=O)O[O-])CCN(CC(=O)[O-])CC2)=C(C)C1=O</smiles>

Yb(DO3A-oAA-TML-Q) [66]

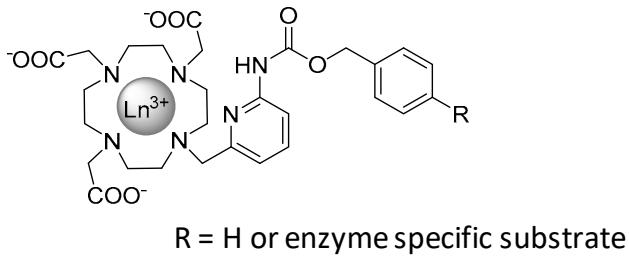

Yb(DO3A-Py) [72]<smiles>[NH3+]CCCCCN1CCN(CC(=O)[O-])CCN(CC(=O)[O-])CCN(CC(=O)[O-])CC1</smiles><smiles>[14CH3][134CH3]</smiles>

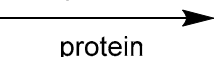

$\operatorname{Tm}$ (DO3A-cadaverine) [68]

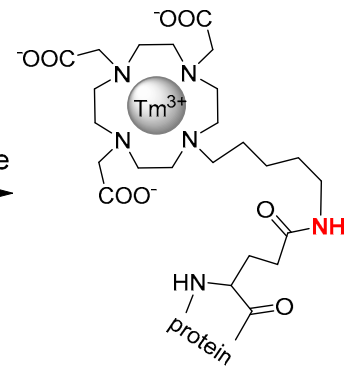

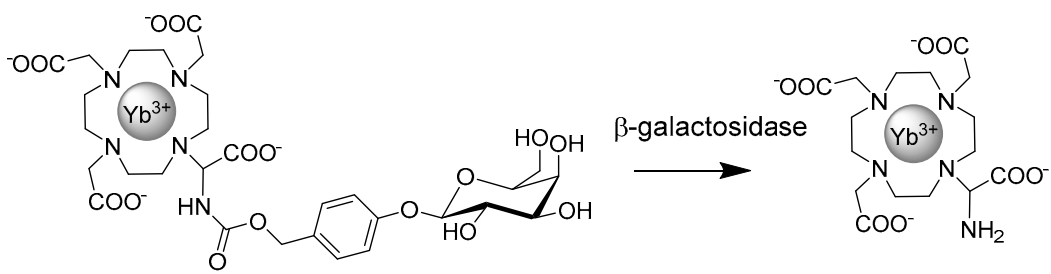

Yb(DOTA-Gal) $[70,71]$

Scheme 5. Enzymatically-activated ParaCEST probes. 
The CatalyCEST strategy was translated to in vivo detection and used for monitoring the urokinase Plasminogen Activator (uPA), a protease biomarker linked to pancreatic tumor invasion and metastases [67]. For this enzyme, which is originally expressed as a pro-enzyme, it is particularly important to detect enzymatic activity and not the simple presence of the enzyme, which might be inactive. As above, $\mathrm{Yb}$ (DOTAM-Gly) was used as a control agent. The responsive agent Tm(DOTA-ZGGR) (Scheme 5) contains a peptide sequence specific of uPA. The simultaneous injection of the control and the uPA responsive ParaCEST probe into a mouse provided the ability to simultaneously track delivery and enzyme catalysis, which allowed for analysis of the enzyme activity in the tumor model.

Proteases are known to be promiscuous with limited selectivity for a given substrate. In future studies, more selective detection of promiscuous proteases could be realized by using multiple CEST agents with distinct resonance frequencies that can be simultaneously detected. In this respect, thanks to its frequency-encoded nature, CEST provides very interesting opportunities to improve detection selectivity and to perform in vivo enzyme kinetic studies, which are not easily accessible by other means today.

Enzymes that catalyze the formation of amide bonds can also be detected by monitoring the CEST effect originating from the amide proton. One example is the $\operatorname{Tm}$ (DO3A-cadaverine) probe (Scheme 5), which can be conjugated to glutamine side chains of proteins by the aid of the enzyme transglutaminase (TGase) [68]. After adding TGase to a sample of Tm(DO3A-cadaverine), albumin and glutathione (a reducing environment is needed for TGase activity), a CEST effect appeared at $-9.2 \mathrm{ppm}$, while the CEST signal from albumin at $+4.6 \mathrm{ppm}$ disappeared. Studies with model peptides gave similar results, though the CEST frequencies and amplitudes changed as a function of the peptide sequence.

In another example, Tm(DOTA-monoamide) was conjugated to a cell penetrating peptide via a peptide sequence that is cleavable by the mammalian lysosomal aspartyl protease cathepsin D [69]. The same molecule also integrated a fluorescent reporter tag for visualization of cellular uptake in cell culture or for future histological post mortem animal studies. This dual optical and ParaCEST MRI agent was expected to be trapped within cells overexpressing cathepsin D following the enzymatic cleavage, which was indeed proved by in vitro fluorescence imaging. CEST imaging was realized on phantoms containing the probe after enzymatic transformation.

Enzymatic ParaCEST probes have been also created using self-immolative units to connect the lanthanide chelate and the enzyme-specific substrate. In Yb(DOTA-Gal) (Scheme 5), the YbDOTA derivative is linked to a $\beta$-D-galactopyranoside substrate via a self-immolative benzyloxycarbamate moiety $[70,71]$. When the $\beta$-galactosidase enzyme cleaves the substrate, it initiates an electron cascade that leads to the spontaneous elimination of the spacer and the formation of an amine function generating a CEST effect. Advantages of self-immolative probes involve better enzyme recognition since the substrate is placed further from the lanthanide complex, and easier chemical strategies to create platforms allowing for adaptation to the detection of various enzymes. The original design was later extended to allow trimodal detection in ParaCEST and $\mathrm{T}_{1}$-weighted MRI, as well as in optical imaging by including in the ligand a pyridylmethyl moiety (Ln(DO3A-Py), Scheme 5) [72]. A single ligand and a common triggering molecular mechanism can be used and only by varying the nature of the lanthanide ion to be complexed, the system can allow for achieving detection in these various imaging modalities. The proton exchange has been studied by accelerated ab initio simulation techniques on the $\mathrm{Eu}^{3+}$ complex of the DO3A derivative substituted by a (6-methylpyridin-2-yl)-carbamate, for which the observed CEST effect is related to the carbamate proton [8]. A good agreement was found between the experimental (on a mixture of square antiprismatic (SA) and twisted square antiprismatic (TSAP) isomers) and the theoretical (focused on the TSAP isomer) proton-exchange rates, suggesting that the two isomers should have similar exchange rates. These ab initio simulations in aqueous solution shed also light for the first time on the reaction mechanism of the proton exchange, which involves structural Grotthuss diffusion. 


\section{Conclusions}

Very quickly after the introduction of ParaCEST agents, various design strategies have been explored to make them responsive to biologically important biomarkers. Since proton exchange, constituting the basis of any chemical exchange saturation transfer experiment, is intrinsically dependent on $\mathrm{pH}, \mathrm{pH}$ sensing has been likely the most active area. In addition, the detection of endogenous metal ions, negatively charged metabolites and DNA, redox states, and enzymatic activities has also met great interest. Although lanthanide complexes represent the majority of responsive ParaCEST probes, transition metal chelates are gaining importance as well.

The great sensitivity of proton exchange processes, thus the generated ParaCEST signal to many different tissue parameters ( $\mathrm{pH}$, temperature, ion composition, etc.) is an advantage for the creation of responsive probes, but on the other hand, it also complicates the unambiguous interpretation of the results and might render in vivo translation more difficult. In this respect, strategies relying on the use of a control agent that is not responsive to the biomarker to be detected, while remaining similarly dependent on other tissue parameters as the responsive probe, are particularly interesting. For this, the frequency encoded character of CEST, especially when associated to large chemical shifts for ParaCEST agents, is a great advantage. It opens new opportunities towards relatively easy ratiometric approaches either by combining two individual agents or two sets of exchanging protons within a single molecular unit, thereby ensuring identical pharmacokinetic behavior of the responsive and the control agent. The possibility of simultaneous detection of more than one ParaCEST agent will be likely further exploited in the future to assess complex enzyme kinetics in vivo, to improve specificity of protease detection, or to provide quantitative mapping of biomarkers.

In vivo applications of ParaCEST agents have been so far limited; nevertheless, they clearly show the feasibility of this detection technique and most importantly evidence that low detection sensitivity is not an absolute obstacle for in vivo translation. The great diversity of chemical designs that allow for creating exchangeable protons with CEST potential has the promise of many new ideas. Furthermore, the conjugation of paramagnetic complexes to responsive systems that have already been validated as diamagnetic CEST sensors can be also interesting to shift the detection frequencies out of the tissue magnetization window. One can thus reasonably expect that the contribution to ParaCEST agents to the field of preclinical molecular MR imaging will continuously grow in the near future.

Funding: This research was funded by the Agence Nationale de la Recherche (grants: Zicores, Diva, Manga), the Région Centre (Enzy-neuro) and the Ligue contre le Cancer, France.

Conflicts of Interest: The authors declare no conflict of interest.

\section{References}

1. Wahsner, J.; Gale, E.M.; Rodríguez-Rodríguez, A.; Caravan, P. Chemistry of MRI Contrast Agents: Current Challenges and New Frontiers. Chem. Rev. 2019, 119, 957-1057. [CrossRef]

2. Hingorani, D.V.; Bernstein, A.S.; Pagel, M.D. A review of responsive MRI contrast agents: 2005-2014. Contrast Media Mol. Imaging 2015, 10, 245-265. [CrossRef]

3. Bonnet, C.S.; Tei, L.; Botta, M.; Toth, E. Responsive probes. In The Chemistry of Contrast Agents in Medical Magnetic Resonance Imaging; Merbach, A.E., Helm, L., Toth, E., Eds.; John Wiley \& Sons: Chichester, UK, 2013; pp. 343-385.

4. Aime, S.; Crich, S.G.; Gianolio, E.; Giovenzana, G.B.; Tei, L.; Terreno, E. High sensitivity lanthanide(III) based probes for MR-medical imaging. Coord. Chem. Rev. 2006, 250, 1562-1579. [CrossRef]

5. Woods, M.; Donald, E.W.C.; Sherry, A.D. Paramagnetic lanthanide complexes as ParaCEST agents for medical imaging. Chem. Soc. Rev. 2006, 35, 500-511. [CrossRef]

6. Ntziachristos, V.; Pleitez, M.A.; Aime, S.; Brindle, K.M. Emerging Technologies to Image Tissue Metabolism. Cell Metab. 2019, 29, 518-538. [CrossRef]

7. Parrott, D.; Fernando, W.S.; Martins, A.F. Smart MRI Agents for Detecting Extracellular Events In Vivo: Progress and Challenges. Inorganics 2019, 7, 18. [CrossRef] 
8. Pollet, R.; Bonnet, C.S.; Retailleau, P.; Durand, P.; Toth, E. Proton Exchange in a Paramagnetic Chemical Exchange Saturation Transfer Agent from Experimental Studies and ab initio Metadynamics Simulation. Inorg. Chem. 2017, 56, 4317-4323. [CrossRef]

9. Wu, Y.; Zhou, Y.; Ouari, O.; Woods, M.; Zhao, P.; Soesbe, T.C.; Kiefer, G.E.; Sherry, A.D. Polymeric PARACEST agents for enhancing MRI contrast sensitivity. J. Am. Chem. Soc. 2008, 130, 13854-13855. [CrossRef] [PubMed]

10. Gatenby, R.A.; Gawlinski, E.T.; Gmitro, A.F.; Kaylor, B.; Gillies, R.J. Acid-mediated tumor invasion: A multidisciplinary study. Cancer Res. 2006, 66, 5216-5223. [CrossRef]

11. Aime, S.; Delli Castelli, D.; Terreno, E. Novel pH-Reporter MRI Contrast Agents. Angew. Chem. Int. Ed. 2002, 41, 4334-4336. [CrossRef]

12. Sheth, V.R.; Li, Y.; Chen, L.Q.; Howison, C.M.; Flask, C.A.; Pagel, M.D. Measuring in vivo tumor pHe with CEST-FISP MRI. Magn. Res. Med. 2012, 67, 760-768. [CrossRef] [PubMed]

13. Sheth, V.R.; Liu, G.; Li, Y.; Pagel, M.D. Improved pH measurements with a single ParaCEST MRI contrast agent. Contrast Media Mol. Imag. 2012, 7, 26-34. [CrossRef] [PubMed]

14. Dorazio, S.J.; Olatunde, A.O.; Spernyak, J.A.; Morrow, J.R. CoCEST: Cobalt (II) amide-appended ParaCEST MRI contrast agents. Chem. Comm. 2013, 49, 10025-10027. [CrossRef]

15. Thorarinsdottir, A.E.; Harris, T.D. Dramatic enhancement in $\mathrm{pH}$ sensitivity and signal intensity through ligand modification of a dicobalt ParaCEST probe. Chem. Comm. 2019, 55, 794-797. [CrossRef] [PubMed]

16. Tsitovich, P.B.; Cox, J.M.; Spernyak, J.A.; Morrow, J.R. Gear Up for a pH Shift: A Responsive Iron (II) 2-Amino-6-picolylAppended Macrocyclic ParaCEST Agent That Protonates at a Pendent Group. Inorg. Chem. 2016, 55, 12001-12010. [CrossRef] [PubMed]

17. Delli Castelli, D.; Terreno, E.; Aime, S. Yb ${ }^{\mathrm{III}}-\mathrm{HPDO}_{3} \mathrm{~A}$ : A Dual pH- and Temperature-Responsive CEST Agent. Angew. Chem. Int. Ed. 2011, 50, 1798-1800. [CrossRef] [PubMed]

18. Thorarinsdottir, A.E.; Du, K.; Collins, J.H.P.; Harris, T.D. Ratiometric $\mathrm{pH}$ Imaging with a $\mathrm{Co}_{2}{ }_{2}$ MRI Probe via CEST Effects of Opposing pH Dependences. J. Am. Chem. Soc. 2017, 139, 15836-15847. [CrossRef]

19. Wu, Y.; Soesbe, T.C.; Kiefer, G.E.; Zhao, P.; Sherry, A.D. A Responsive Europium(III) Chelate That Provides a Direct Readout of pH by MRI. J. Am. Chem. Soc. 2010, 132, 14002-14003. [CrossRef]

20. Zhang, L.; Martins, A.F.; Zhao, P.; Wu, Y.; Tircso, G.; Sherry, A.D. Lanthanide-Based T-2ex and CEST Complexes Provide Insights into the Design of pH Sensitive MRI Agents. Angew. Chem. Int. Ed. 2017, 56, 16626-16630. [CrossRef]

21. Aime, S.; Barge, A.; Delli Castelli, D.; Fedeli, F.; Mortillaro, A.; Nielsen, F.U.; Terreno, E. Paramagnetic Lanthanide (III) complexes as $\mathrm{pH}$-sensitive chemical exchange saturation transfer (CEST) contrast agents for MRI applications. Magn. Res. Med. 2002, 47, 639-648. [CrossRef]

22. Liu, G.; Li, Y.; Sheth, V.R.; Pagel, M.D. Imaging In Vivo Extracellular pH with a Single Paramagnetic Chemical Exchange Saturation Transfer Magnetic Resonance Imaging Contrast Agent. Mol. Imaging 2012, 11, 47-57. [CrossRef] [PubMed]

23. Castelli, D.D.; Ferrauto, G.; Carlos Cutrin, J.; Terreno, E.; Aime, S. In Vivo Maps of Extracellular pH in Murine Melanoma by CEST-MRI. Magn. Res. Med. 2014, 71, 326-332. [CrossRef] [PubMed]

24. Wu, Y.; Zhang, S.; Soesbe, T.C.; Yu, J.; Vinogradov, E.; Lenkinski, R.E.; Sherry, A.D. pH Imaging of Mouse Kidneys In Vivo Using a Frequency-Dependent ParaCEST Agent. Magn. Res. Med. 2016, 75, 2432-2441. [CrossRef] [PubMed]

25. Wang, X.; Wu, Y.; Soesbe, T.C.; Yu, J.; Zhao, P.; Kiefer, G.E.; Sherry, A.D. A pH-Responsive MRI Agent that Can Be Activated Beyond the Tissue Magnetization Transfer Window. Angew. Chem. Int. Ed. 2015, 54, 8662-8664. [CrossRef] [PubMed]

26. McVicar, N.; Li, A.X.; Suchy, M.; Hudson, R.H.E.; Menon, R.S.; Bartha, R. Simultaneous In Vivo pH and Temperature Mapping Using a ParaCEST-MRI Contrast Agent. Magn. Res. Med. 2013, 70, 1016-1025. [CrossRef] [PubMed]

27. Pikkemaat, J.A.; Wegh, R.T.; Lamerichs, R.; van de Molengraaf, R.A.; Langereis, S.; Burdinski, D.; Raymond, A.Y.F.; Janssen, H.M.; de Waal, B.F.M.; Willard, N.P.; et al. Dendritic ParaCEST contrast agents for magnetic resonance imaging. Contrast Media Mol. Imaging 2007, 2, 229-239. [CrossRef]

28. Palmer, A.E.; Franz, K.J. Introduction to Cellular Metal Homeostasis and Trafficking. Chem. Rev. 2009, 109, 4533-4535. [CrossRef] 
29. Que, E.L.; Domaille, D.W.; Chang, C.J. Metals in neurobiology: Probing their chemistry and biology with molecular imaging. Chem. Rev. 2008, 108, 1517-1549. [CrossRef] [PubMed]

30. Eide, D.J. The oxidative stress of zinc deficiency. Metallomics 2011, 3, 1124-1129. [CrossRef]

31. Bonnet, C.S.; Toth, E. Smart Contrast Agents for Magnetic Resonance Imaging. Chimia 2016, 70, $102-108$. [CrossRef]

32. Angelovski, G.; Chauvin, T.; Pohmann, R.; Logothetis, N.K.; Toth, E. Calcium-responsive paramagnetic CEST agents. Bioorg. Med. Chem. 2011, 19, 1097-1105. [CrossRef]

33. Cakic, N.; Verbic, T.Z.; Jelic, R.M.; Platas-Iglesias, C.; Angelovski, G. Synthesis and characterisation of bismacrocyclic DO3A-amide derivatives-An approach towards metal-responsive ParaCEST agents. Dalton Trans. 2016, 45, 6555-6565. [CrossRef]

34. Angelovski, G.; Fouskova, P.; Mamedov, I.; Canals, S.; Toth, E.; Logothetis, N.K. Smart magnetic resonance imaging agents that sense extracellular calcium fluctuations. Chembiochem 2008, 9, 1729-1734. [CrossRef] [PubMed]

35. Toth, E.; Helm, L.; Merbach, A.E. Relaxivity of Gadolinium (III) Complexes: Theory and Mechanism. In The Chemistry of Contrast Agents in Medical Magnetic Resonance Imaging, 2nd ed.; Merbach, A.E., Helm, L., Toth, E., Eds.; John Wiley \& Sons: Chichester, UK, 2013; pp. 25-81.

36. Lubag, A.J.M.; De Leon-Rodriguez, L.M.; Burgess, S.C.; Sherry, A.D. Noninvasive MRI of $\beta$-cell function using a $\mathrm{Zn}^{2+}$-responsive contrast agent. Proc. Natl. Acad. Sci. USA 2011, 108, 18400-18405. [CrossRef] [PubMed]

37. Jordan, M.V.C.; Lo, S.-T.; Chen, S.; Preihs, C.; Chirayil, S.; Zhang, S.; Kapur, P.; Li, W.-H.; De Leon-Rodriguez, L.M.; Lubag, A.J.M.; et al. Zinc-sensitive MRI contrast agent detects differential release of $\mathrm{Zn}$ (II) ions from the healthy vs. malignant mouse prostate. Proc. Natl. Acad. Sci. USA 2016, 113, E5464-E5471. [CrossRef] [PubMed]

38. Srivastava, K.; Ferrauto, G.; Harris, S.M.; Longo, D.L.; Botta, M.; Aime, S.; Pierre, V.C. Complete on/off responsive ParaCEST MRI contrast agents for copper and zinc. Dalton Trans. 2018, 47, 11346-11357. [CrossRef]

39. Que, E.L.; Gianolio, E.; Baker, S.L.; Wong, A.P.; Aime, S.; Chang, C.J. Copper-Responsive Magnetic Resonance Imaging Contrast Agents. J. Am. Chem. Soc. 2009, 131, 8527-8536. [CrossRef]

40. Wu, Y.; Carney, C.E.; Denton, M.; Hart, E.; Zhao, P.; Streblow, D.N.; Sherry, A.D.; Woods, M. Polymeric ParaCEST MRI contrast agents as potential reporters for gene therapy. Org. Biomol. Chem. 2010, 8, 5333-5338. [CrossRef]

41. Nwe, K.; Andolina, C.M.; Huang, C.-H.; Morrow, J.R. ParaCEST Properties of a Dinuclear Neodymium(III) Complex Bound to DNA or Carbonate. Bioconj. Chem. 2009, 20, 1375-1382. [CrossRef]

42. Gatenby, R.A.; Gillies, R.J. Why do cancers have high aerobic glycolysis? Nat. Rev. Cancer 2004, 4, 891. [CrossRef]

43. Surman, A.J.; Bonnet, C.S.; Lowe, M.P.; Kenny, G.D.; Bell, J.D.; Tóth, É.; Vilar, R. A Pyrophosphate-Responsive Gadolinium(III) MRI Contrast Agent. Chem. Eur. J. 2011, 17, 223-230. [CrossRef] [PubMed]

44. Huang, C.-H.; Morrow, J.R. A ParaCEST Agent Responsive to Inner- And Outer-Sphere Phosphate Ester Interactions for MRI Applications. J. Am. Chem. Soc. 2009, 131, 4206-4207. [CrossRef]

45. Huang, C.-H.; Hammell, J.; Ratnakar, S.J.; Sherry, A.D.; Morrow, J.R. Activation of a ParaCEST Agent for MRI through Selective Outersphere Interactions with Phosphate Diesters. Inorg. Chem. 2010, 49, 5963-5970. [CrossRef] [PubMed]

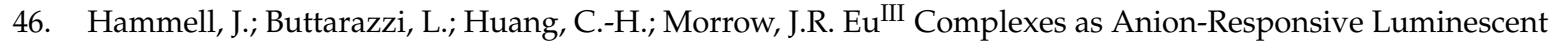
Sensors and Paramagnetic Chemical Exchange Saturation Transfer Agents. Inorg. Chem. 2011, 50, 4857-4867. [CrossRef]

47. Zhang, S.; Trokowski, R.; Sherry, A.D. A Paramagnetic CEST Agent for Imaging Glucose by MRI. J. Am. Chem. Soc. 2003, 125, 15288-15289. [CrossRef] [PubMed]

48. Trokowski, R.; Zhang, S.; Sherry, A.D. Cyclen-Based Phenylboronate Ligands and Their Eu ${ }^{3+}$ Complexes for Sensing Glucose by MRI. Bioconj. Chem. 2004, 15, 1431-1440. [CrossRef] [PubMed]

49. Zhang, L.; Martins, A.F.; Mai, Y.; Zhao, P.; Funk, A.M.; Clavijo Jordan, M.V.; Zhang, S.; Chen, W.; Wu, Y.; Sherry, A.D. Imaging Extracellular Lactate In Vitro and In Vivo Using CEST MRI and a Paramagnetic Shift Reagent. Chem. Eur. J. 2017, 23, 1752-1756. [CrossRef] 
50. Zhang, L.; Martins, A.F.; Zhao, P.; Tieu, M.; Esteban-Gomez, D.; McCandless, G.T.; Platas-Iglesias, C.; Sherry, A.D. Enantiomeric Recognition of D- and L-Lactate by CEST with the Aid of a Paramagnetic Shift Reagent. J. Am. Chem. Soc. 2017, 139, 17431-17437. [CrossRef]

51. Ren, J.; Trokowski, R.; Zhang, S.; Malloy, C.R.; Sherry, A.D. Imaging the Tissue Distribution of Glucose in Livers Using A ParaCEST Sensor. Magn. Res. Med. 2008, 60, 1047-1055. [CrossRef]

52. Tsitovich, P.B.; Burns, P.J.; McKay, A.M.; Morrow, J.R. Redox-activated MRI contrast agents based on lanthanide and transition metal ions. J. Inorg. Biochem. 2014, 133, 143-154. [CrossRef]

53. Tsitovich, P.B.; Spernyak, J.A.; Morrow, J.R. A Redox-Activated MRI Contrast Agent that Switches Between Paramagnetic and Diamagnetic States. Angew. Chem. Int. Ed. 2013, 52, 13997-14000. [CrossRef] [PubMed]

54. Ekanger, L.A.; Ali, M.M.; Allen, M.J. Oxidation-responsive $\mathrm{Eu}^{2+}{ }^{3+}$-liposomal contrast agent for dual-mode magnetic resonance imaging. Chem. Comm. 2014, 50, 14835-14838. [CrossRef]

55. Terreno, E.; Boffa, C.; Menchise, V.; Fedeli, F.; Carrera, C.; Castelli, D.D.; Digilio, G.; Aime, S. Gadolinium-doped LipoCEST agents: A potential novel class of dual ${ }^{1} \mathrm{H}-\mathrm{MRI}$ probes. Chem. Commun. 2011, 47, 4667-4669. [CrossRef]

56. Ratnakar, S.J.; Soesbe, T.C.; Lumata, L.L.; Do, Q.N.; Viswanathan, S.; Lin, C.-Y.; Sherry, A.D.; Kovacs, Z. Modulation of CEST Images in Vivo by T1 Relaxation: A New Approach in the Design of Responsive ParaCEST Agents. J. Am. Chem. Soc. 2013, 135, 14904-14907. [CrossRef] [PubMed]

57. Liu, G.; Li, Y.; Pagel, M.D. Design and characterization of a new irreversible responsive ParaCEST MRI contrast agent that detects nitric oxide. Magn. Res. Med. 2007, 58, 1249-1256. [CrossRef] [PubMed]

58. Ratnakar, S.J.; Woods, M.; Lubag, A.J.M.; Kovács, Z.; Sherry, A.D. Modulation of Water Exchange in Europium(III) DOTA-Tetraamide Complexes via Electronic Substituent Effects. J. Am. Chem. Soc. 2008, 130, 6-7. [CrossRef]

59. Ratnakar, S.J.; Viswanathan, S.; Kovacs, Z.; Jindal, A.K.; Green, K.N.; Sherry, A.D. Europium(III) DOTA-tetraamide Complexes as Redox-Active MRI Sensors. J. Am. Chem. Soc. 2012, 134, 5798-5800. [CrossRef]

60. Song, B.; Wu, Y.; Yu, M.; Zhao, P.; Zhou, C.; Kiefer, G.E.; Sherry, A.D. A europium(III)-based ParaCEST agent for sensing singlet oxygen by MRI. Dalton Trans. 2013, 42, 8066-8069. [CrossRef] [PubMed]

61. Suchy, M.; Li, A.X.; Bartha, R.; Hudson, R.H.E. Synthesis of MRI contrast agents derived from DOTAM-Gly-L-Phe-OH incorporating a disulfide bridge: Conjugation to a cell penetrating peptide and preparation of a dimeric agent. Bioorg. Med. Chem. Lett. 2010, 20, 5521-5526. [CrossRef]

62. Moats, R.A.; Fraser, S.E.; Meade, T.J. A “Smart” Magnetic Resonance Imaging Agent That Reports on Specific Enzymatic Activity. Angew. Chem. Int. Ed. 1997, 36, 726-728. [CrossRef]

63. Yoo, B.; Pagel, M.D. A ParaCEST MRI Contrast Agent To Detect Enzyme Activity. J. Am. Chem. Soc. 2006, 128, 14032-14033. [CrossRef]

64. Yoo, B.; Raam, M.S.; Rosenblum, R.M.; Pagel, M.D. Enzyme-responsive ParaCEST MRI contrast agents: A new biomedical imaging approach for studies of the proteasome. Contrast Media Mol. Imaging 2007, 2, 189-198. [CrossRef]

65. Li, Y.; Sheth, V.R.; Liu, G.; Pagel, M.D. A self-calibrating ParaCEST MRI contrast agent that detects esterase enzyme activity. Contrast Media Mol. Imaging 2011, 6, 219-228. [CrossRef]

66. Daryaei, I.; Jones, K.M.; Pagel, M.D. Detection of DT-diaphorase Enzyme with a ParaCEST MRI Contrast Agent. Chem. Eur. J. 2017, 23, 6514-6517. [CrossRef]

67. Yoo, B.; Sheth, V.R.; Howison, C.M.; Douglas, M.J.K.; Pineda, C.T.; Maine, E.A.; Baker, A.F.; Pagel, M.D. Detection of in vivo enzyme activity with CatalyCEST MRI. Magn. Res. Med. 2014, 71, 1221-1230. [CrossRef]

68. Hingorani, D.V.; Randtke, E.A.; Pagel, M.D. A CatalyCEST MRI Contrast Agent That Detects the Enzyme-Catalyzed Creation of a Covalent Bond. J. Am. Chem. Soc. 2013, 135, 6396-6398. [CrossRef]

69. Suchý, M.; Ta, R.; Li, A.X.; Wojciechowski, F.; Pasternak, S.H.; Bartha, R.; Hudson, R.H.E. A paramagnetic chemical exchange-based MRI probe metabolized by cathepsin D: Design, synthesis and cellular uptake studies. Org. Biomol. Chem. 2010, 8, 2560-2566. [CrossRef]

70. Chauvin, T.; Durand, P.; Bernier, M.; Meudal, H.; Doan, B.T.; Noury, F.; Badet, B.; Beloeil, J.C.; Toth, E. Detection of enzymatic activity by ParaCEST MRI: A general approach to target a large variety of enzymes. Angew. Chem. Int. Ed. 2008, 47, 4370-4372. [CrossRef] 
71. Chauvin, T.; Torres, S.; Rosseto, R.; Kotek, J.; Badet, B.; Durand, P.; Tóth, É. Lanthanide (III) Complexes That Contain a Self-Immolative Arm: Potential Enzyme Responsive Contrast Agents for Magnetic Resonance Imaging. Chem. Eur. J. 2012, 18, 1408-1418. [CrossRef]

72. He, J.; Bonnet, C.S.; Eliseeva, S.V.; Lacerda, S.; Chauvin, T.; Retailleau, P.; Szeremeta, F.; Badet, B.; Petoud, S.; Toth, E.; et al. Prototypes of Lanthanide(III) Agents Responsive to Enzymatic Activities in Three Complementary Imaging Modalities: Visible/Near-Infrared Luminescence, ParaCEST-, and T-1-MRI. J. Am. Chem. Soc. 2016, 138, 2913-2916. [CrossRef]

(C) 2019 by the authors. Licensee MDPI, Basel, Switzerland. This article is an open access article distributed under the terms and conditions of the Creative Commons Attribution (CC BY) license (http://creativecommons.org/licenses/by/4.0/). 